\title{
Improved prediction of bone mineral content and density
}

\author{
W J Hannan, S J Cowen, R M Wrate, J Barton
}

\begin{abstract}
To establish improved predictive values for normal bone mineral content (BMC) and density (BMD) in adolescent girls a community based study of schoolgirl volunteers was carried out by dual energy $x$ ray absorptimetry. Measurements were performed on 216 subjects aged 11.0 to 17.9 years; measurements were repeated one year later on 84 of the girls, providing a total of 300 studies. For total body BMC the standard error of the prediction was improved from $290.9 \mathrm{~g}$ to $134.1 \mathrm{~g}$ when weight, height, and shoulder width were added to the normal variable of age. For spine BMD the standard error of the prediction was improved from $0.105 \mathrm{~g} / \mathrm{cm}^{2}$ to $0.066 \mathrm{~g} / \mathrm{cm}^{2}$ when height, weight, and shoulder width were added to the normal variable of age. Significant improvements were also obtained for total BMD and spine BMC. Despite the normal practice of predicting bone density from age alone this was not selected as the first variable in a multiple stepwise regression for either total body or spine. The prediction of BMC and BMD can be significantly improved by the inclusion of simple body habitus parameters in the prediction equations. As the mean (SE) $z$ score derived from the manufacturer's normal data was $-0.36(0.02)$ these American data are probably not appropriate for use in adolescents in the UK.

(Arch Dis Child 1995; 72: 147-149)
\end{abstract}

Keywords: dual energy $x$ ray, absorptiometry, bone density, adolescent girls.

The attainment of a high peak bone mass towards the end of the third decade of life is considered an important protective factor in the development of osteoporosis in women later in life. ${ }^{12}$ Maximum bone accretion occurs during adolescence, ${ }^{34}$ when compared with adults very high concentrations of biochemical markers of bone formation and resorption are found. ${ }^{5}$ In addition to the probable influences of diet, exercise, and genetic factors, ${ }^{1}$ oestradiol plays an important part in bone accretion during adolescence. ${ }^{6}$ For example the malnutrition induced ovulatory disturbances found in anorexia nervosa are assumed to be responsible for the osteopenia commonly associated with this condition. ${ }^{78}$ The age corrected range of normal values of bone density in adolescence none the less demonstrates considerable individual variation, ${ }^{910}$ so unless gross osteopenia is present it is difficult to know from a single bone density study whether the values found may be normal for that subject or whether bone loss has probably occurred. The low radiation dose associated with dual energy $x$ ray absorptiometry (DXA) permits repeated measurement but in children with diseases impairing bone metabolism repeated measurement is of no value in the short term. We describe a study on adolescent girls designed to assist clinical interpretation of bone density estimates by improving its prediction by the inclusion of simple body habitus parameters.

\section{Subjects and methods}

A normal volunteer study was carried out of total and spine bone mineral on young adolescent high school girls, who were taking part in a community based prospective study of the psychobiological correlates of disturbed eating patterns in adolescence. The study was approved by the schools and the appropriate medical ethics committee, and informed consent was obtained from the parents of the participating girls as well as from the girls themselves. Girls were recruited from two schools in Edinburgh, one predominantly middle class and the other predominantly working class. Of those invited to take part approximately a third did so. A total of 216 girls took part, aged between 11.0 and 17.9 years (mean (SD) 13.4 (1.2) years). An additional study was performed on 84 of the original girls one year later, giving a total of 300 measurements. The cohort included five non-white girls, but none were of black African descent where higher bone mineral levels have been observed. ${ }^{10}$ The characteristics of the girls at the time of the 300 measurements are summarised in table 1 ; although eating attitude disturbances were common, none were suffering from a formal eating disorder.

Bone mineral content (BMC) and bone mineral density (BMD), defined as the BMC per unit area, were measured by DXA using a Hologic QDR-1000W machine (Hologic Inc). Each subject was scanned twice to provide separate lumbar spine and total body measurements. Total imaging time was typically 20

Table 1 Characteristics of the girls studied

\begin{tabular}{lrc}
\hline & Mean $(S D)$ & \multicolumn{1}{c}{ Range } \\
\hline Age (years) & $13 \cdot 4(1 \cdot 2)$ & $11 \cdot 0-17 \cdot 9$ \\
Weight $(\mathrm{kg})$ & $50 \cdot 2(9 \cdot 9)$ & $26 \cdot 3-84 \cdot 6$ \\
Height $(\mathrm{cm})$ & $157 \cdot 7(7 \cdot 9)$ & $133 \cdot 8-178 \cdot 1$ \\
Body mass index $\left(\mathrm{kg} / \mathrm{m}^{2}\right)$ & $20 \cdot 1(2 \cdot 9)$ & $13 \cdot 9-29 \cdot 8$ \\
$\%$ Fat & $26 \cdot 3(5 \cdot 5)$ & $15 \cdot 1-46 \cdot 0$ \\
\hline
\end{tabular}

Correspondence to: Dr Hannan.

Accepted 25 October 1994 
Table 2 Prediction of $B M C$ and $B M D$ in adolescent girls. Variables are listed in the order in which they contributed to the prediction equation. $A=$ age (years), $W=$ weight (kg), $H=$ height $(\mathrm{cm})$, and $S=$ shoulder width $(\mathrm{cm})$. The $S E$ of the prediction is also shown

\begin{tabular}{|c|c|c|}
\hline Variables & Prediction equation & $\begin{array}{l}\text { SE of } \\
\text { prediction }\end{array}$ \\
\hline \multicolumn{3}{|l|}{ Total BMC } \\
\hline $\begin{array}{l}\text { A } \\
\text { W, H, A, S } \\
\text { W, H, A }\end{array}$ & $\begin{array}{l}890 \cdot 4 \mathrm{~A}-25 \cdot 04 \mathrm{~A}^{2}-5742 \cdot 9 \\
18 \cdot 34 \mathrm{~W}+11 \cdot 55 \mathrm{H}+296 \cdot 5 \mathrm{~A}-8.34 \mathrm{~A}^{2}+22 \cdot 8 \mathrm{~S}-4353 \cdot 1 \\
20 \cdot 31 \mathrm{~W}+14.69 \mathrm{H}+274 \mathrm{~A}-7.56 \mathrm{~A}^{2}-3988 \cdot 7\end{array}$ & $\begin{array}{l}290 \cdot 9 \mathrm{~g} \\
134 \cdot 1 \mathrm{~g} \\
150 \cdot 8 \mathrm{~g}\end{array}$ \\
\hline \multicolumn{3}{|c|}{$20.31 \mathrm{~W}+14.09 \mathrm{~N}+214 \mathrm{~A}-1.20 \mathrm{~A}-5900.6$} \\
\hline $\begin{array}{l}\text { A } \\
\text { W, A, S } \\
\text { W, A, H }\end{array}$ & $\begin{array}{l}0.127 \mathrm{~A}-0.00296 \mathrm{~A}^{2}-0.221 \\
0.00326 \mathrm{~W}+0.0715 \mathrm{~A}-0.00167 \mathrm{~A}^{2}+0.0098 \mathrm{~S}-0.217 \\
0.00407 \mathrm{~W}+0.0696 \mathrm{~A}-0.00162 \mathrm{~A}^{2}+0.00145 \mathrm{H}-0.125\end{array}$ & $\begin{array}{l}0.069 \mathrm{~g} / \mathrm{cm}^{2} \\
0.042 \mathrm{~g} / \mathrm{cm}^{2} \\
0.044 \mathrm{~g} / \mathrm{cm}^{2}\end{array}$ \\
\hline \multicolumn{3}{|c|}{$0.00407 W+0.0696 \mathrm{~A}-0.00162 \mathrm{~A}^{2}+0.00145 \mathrm{H}-0.125$} \\
\hline $\begin{array}{l}\text { A } \\
\text { H, A, W, W }\end{array}$ & $\begin{array}{l}27 \cdot 18 \mathrm{~A}-0.75 \mathrm{~A}^{2}-187 \cdot 8 \\
0 \cdot 612 \mathrm{H}+12 \cdot 07 \mathrm{~A}-0.333 \mathrm{~A}^{2}+0 \cdot 218 \mathrm{~W}+0.582 \mathrm{~S}-188 \cdot 7 \\
0.692 \mathrm{H}+11.93 \mathrm{~A}-0.329 \mathrm{~A}^{2}+0 \cdot 269 \mathrm{~W}-182 \cdot 45\end{array}$ & $\begin{array}{l}8 \cdot 9 \mathrm{~g} \\
5 \cdot 3 \mathrm{~g} \\
5 \cdot 5 \mathrm{~g}\end{array}$ \\
\hline \multicolumn{3}{|l|}{ Spine BMD } \\
\hline $\begin{array}{l}\text { A } \\
\text { H, A, W, S } \\
\text { H, A, W }\end{array}$ & $\begin{array}{l}0.309 \mathrm{~A}-0.00862 \mathrm{~A}^{2}-1.749 \\
0.00386 \mathrm{H}+0.166 \mathrm{~A}-0.00464 \mathrm{~A}^{2}+0.00308 \mathrm{~W}+0.00779 \mathrm{~S}-1.596 \\
0.00494 \mathrm{H}+0.164 \mathrm{~A}-0.005 \mathrm{~A}^{2}+0.00376 \mathrm{~W}-1.512\end{array}$ & $\begin{array}{l}0.105 \mathrm{~g} / \mathrm{cm}^{2} \\
0.066 \mathrm{~g} / \mathrm{cm}^{2} \\
0.069 \mathrm{~g} / \mathrm{cm}^{2}\end{array}$ \\
\hline
\end{tabular}

minutes and the effective dose was only $6 \mu \mathrm{Sv}$ which is equivalent to the average daily natural background radiation in the UK. For the spine the bone mineral was analysed for vertebrae L1-L4; for the total body individual regions may be analysed but for the present study all regions were summed to give the total body measurement.

Weight was measured on digital scales with a precision of $0.1 \mathrm{~kg}$; patients wore a light gown the weight of which was subtracted from the reading. Height was measured using a wall stadiometer (precision $5 \mathrm{~mm}$ ) with the patient standing upright and without shoes. The anteroposterior thickness was measured using calipers and was taken as the maximum thickness along the full length of the sternum. Shoulder width was also measured using calipers. Tanner pubertal staging was also obtained.

The data were analysed using the Unistat Statistical Package (Unistat Ltd, PO Box 383, Highgate, London N6 5UP). The normal values supplied by DXA manufacturers are presented as a function of age only and are derived from white North Americans. We therefore first derived prediction equations for the BMC and BMD of the spine and total body using only age as the independent variable. The additional body habitus parameters were then added as independent variables and multiple stepwise regression was used to derive alternative prediction equations. Variables were only included in the prediction equation if they resulted in a significant reduction in the standard error (SE) of the prediction.

\section{Results}

In this group of adolescent girls lumbar spine BMC ranged from 16.5 to $77.6 \mathrm{~g}$ and total BMC from 754.7 to $3024.4 \mathrm{~g}$. Lumbar spine BMD ranged from $0.518 \mathrm{~g} / \mathrm{cm}^{2}$ to $1.232 \mathrm{~g} / \mathrm{cm}^{2}$ and total BMD from $0.699 \mathrm{~g} / \mathrm{cm}^{2}$ to 1.256 $\mathrm{g} / \mathrm{cm}^{2}$. The manufacturer supplies normal data and expresses the subject's spine BMD in terms of a $\mathrm{z}$ score, which is the number of standard deviations from the mean of the age matched normals. For a sufficiently large number of normal subjects one would therefore expect the mean $\mathrm{z}$ score to be close to zero, whereas for this cohort the mean (SE) z score was $-0.36(0.02)$. The deviation was even more significant in the younger subjects; for girls aged $11.0-11.9$ years $(n=22), 12 \cdot 0-12.9$ years $(n=118)$, and $13.0-13.9$ years $(n=88)$ the mean (SE) z scores were $-0.79(0.21)$, $-0.55(0.10)$, and $-0.30(0.12)$ respectively. This indicates that the data for subjects in the USA supplied by the manufacturer are not appropriate in this group, particularly in the younger age range.

The prediction equations based on age are summarised in table 2 ; in each case the use of a second degree polynomial provided the optimum fit. The prediction equations obtained when various body habitus parameters were included, in addition to age, are also listed in table 2 . The variables are listed in the order in which they contribute to the prediction equation. The inclusion of anteroposterior thickness and Tanner stage did not improve the predictions. In each case a significant reduction in the error of prediction was obtained by including body habitus parameters in the prediction equation. Indeed it is seen that age is not selected as the most important variable in any of the prediction equations where the additional body habitus variables are included. Table 2 shows that the best prediction always includes the subject's weight. Since the inclusion of shoulder width provided only a relatively small improvement in the SE of the prediction table 2 provides alternative prediction equations which do not include shoulder width.
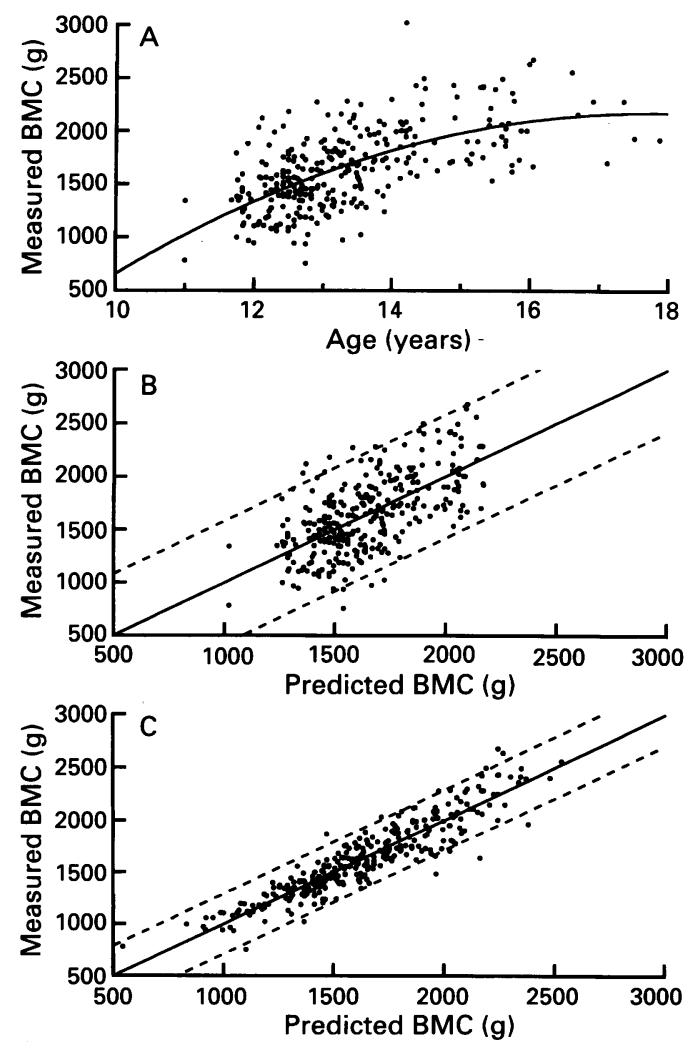

Figure 1 (A) Total BMC in normal adolescent girls as a function of age, where the line corresponds to the prediction based on age listed in table $2 ;(B)$ total BMC compared with values predicted from age, where the solid line is the least squares fit and the broken lines are the $95 \%$ confidence intervals; (C) total BMC compared with the values predicted from weight, height, age and shoulder width, where the solid and broken lines are the least squares fit and $95 \%$ confidence intervals respectively. 

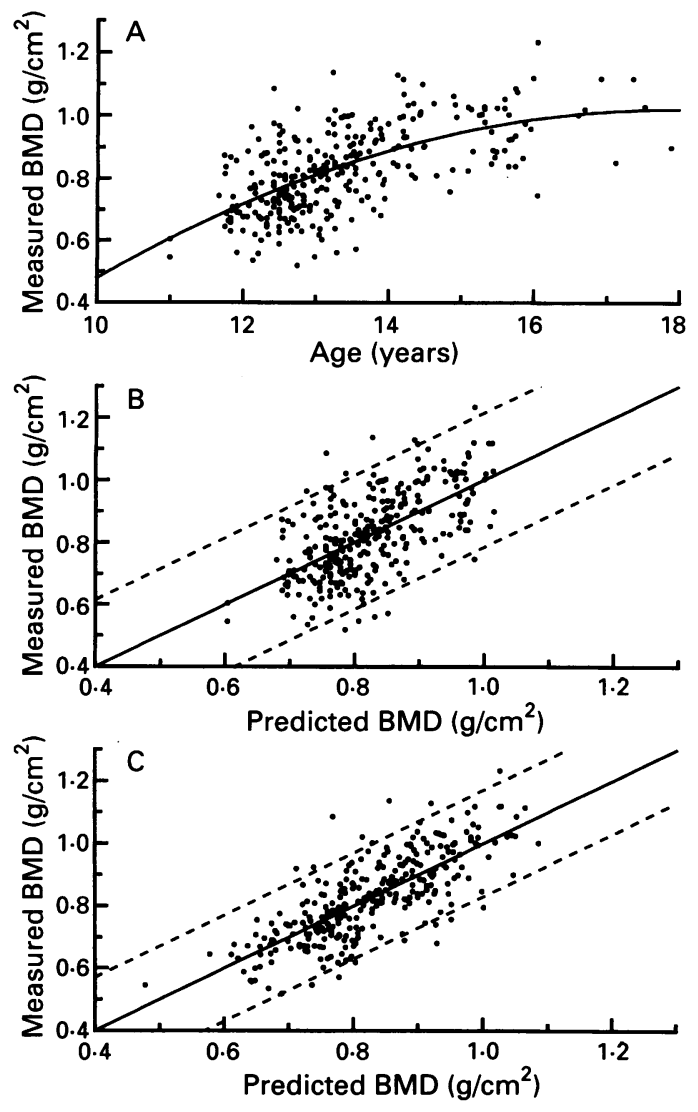

Figure 2 (A) BMD for lumbar vertebrae L1-L4 in normal adolescent girls as a function of age, where the line corresponds to the prediction based on age listed in table 2; (B) spine BMD compared with the values predicted from age, where the solid line is the least squares fit and the broken lines are the 95\% confidence intervals; (C) spine BMD compared with the values predicted from height, age, weight and shoulder width, where the solid and broken lines are the least squares fit and the $95 \%$ confidence intervals respectively.

The significance of the improved predictions may be more readily appreciated by comparing plots of the predicted data. Figure 1A shows total $\mathrm{BMC}$ as a function of age where the line corresponds to the prediction equation listed in table 2. Figure 1B compares the measured $\mathrm{BMC}$ with the values derived from this prediction equation; the solid line is the least squares fit and the broken lines represent the 95\% confidence intervals. Figure 1C shows the measured BMC compared with the prediction based on weight, height, age and shoulder width, where the solid and broken lines again represent the least squares fit and 95\% confidence intervals respectively. For the spine bone mineral is usually presented as $\mathrm{BMD}$, where the projected area is effectively used to try to normalise for differences in body stature. Figure $2 \mathrm{~A}$ shows spine $\mathrm{BMD}$ as a function of age where the line represents the prediction equation listed in table 2 . Figure $2 \mathrm{~B}$ compares the measured $\mathrm{BMD}$ with the values derived using this prediction equation and fig $2 \mathrm{C}$ compares the measured $\mathrm{BMD}$ with the values predicted from height, age, weight and shoulder width, where the solid and broken lines again represent the least squares fits and $95 \%$ confidence intervals respectively.
Since the various prediction equations were derived by multiple stepwise regression the mean $\mathrm{z}$ scores for the entire age range were, as would be expected, not significantly different from zero. To check if this applied equally throughout the age range the mean $\mathrm{z}$ scores were calculated separately for one year age intervals and were similarly found to be not significantly different from zero.

\section{Discussion}

This study set out to examine to what extent the wide variation previously observed in BMC and $\mathrm{BMD}$ in adolescents ${ }^{39}$ could be attributed to individual differences in body habitus parameters as well as to age, since this would assist the clinical interpretation of deviations from normal. We have shown that a considerable proportion of the variation in spine and total body BMC and BMD is in fact attributable to differences in body stature. For the spine it is normally the BMD that is considered more meaningful since this includes some normalisation for body stature. The variation in spine $B M D$ is in fact significantly less than the corresponding variation in BMC. However, age was not the major determinant of spine BMD and a significant reduction in the SE of the prediction was obtained by including height, weight and shoulder width in the prediction equation. Although there is a significant relationship between BMD and Tanner stage this was not selected as a variable in the multiple stepwise regression, presumably because it is not a continuous variable and because it is not independent, being itself related to the body habitus parameters.

In our cohort of adolescent females the mean $\mathrm{z}$ scores using the manufacturer's normal data were significantly lower than zero. Caution should therefore be shown when using the normal data for this age group supplied by the manufacturer, particularly in the younger subjects.

1 Ott SM. Attainment of peak bone mass [Editorial]. $f$ Clin Endocrinol Metab 1990; 71: 1082A-1082C.

2 Johnston CC, Longcope C. Premenopausal bone loss - a risk factor for osteoporosis. N Engl f Med 1991; 323: 1271-2.

3 Theintz G, Buchs B, Rizzoli R, et al. Longitudinal monitoring of bone mass accumulation in healthy adolescents: evidence for a marked reduction after 16 years of age at the levels of lumbar spine and femoral neck in female subjects. f Clin Endocrinol Metab 1992; 75: 1060-5.

4 Davie MWJ, Haddaway MJ. Bone mineral content and density in healthy subjects and in osteogenesis imperfecta. Arch Dis Child 1994; 70: 331-4.

5 Blumsohn A, Hannon RA, Wrate RM, et al. Biochemical markers of bone turnover in girls during puberty. Clin Endocrinol (Oxf) 1994; 40: 663-70.

6 Dhuper S, Warren MP, Brooks-Gunn J, Fox R. Effects of hormonal status on bone density in adolescent girls. $\mathcal{F}$ Clin Endocrinol Metab 1990; 71: 1083-8.

7 Bachrach LK, Guido D, Katzman D, Litt IF, Marcus R. Decreased bone density in adolescent girls with anorexia nervosa. Pediatrics 1990; 86: 440-7.

8 Bachrach LK, Katzman DK, Litt IF, Guido D, Marcus R. Recovery from oestopenia in adolescent girls with anorexia nervosa. F Clin Endocrinol Metab 1991; 72: 602-6.

9 Glastre C, Braillon P, Louis D, Cochat P, Meunier PJ, Delmas PD. Measurement of bone mineral content of the lumbar spine by dual energy $\mathrm{X}$-ray absorptiometry in normal children: correlations with growth parameters. $\mathcal{F}$ Clin Endocrinol Metab 1990; 70: 1330-3.

10 Gilsanz V, Roe TF, Mora S, Costin G, Goodman WG. Changes in vertebral bone density in black girls and white girls during childhood and puberty. $N$ Engl $₹$ Med 1991; 325: $1597-600$. 